\title{
Improving trainee colonoscopy performance by investigating the withdrawal time from individual colonic segments: a single-center observational study
}

\author{
Yinshi Huang", Feifan Chen", Gang Xu", Li Huang, Rong Wan, Lijuan Yang, Congying Chen \\ Department of Gastroenterology, Shanghai General Hospital, Shanghai Jiao Tong University School of Medicine, Shanghai, China \\ Contributions: (I) Conception and design: C Chen; (II) Administrative support: L Yang; (III) Provision of study materials or patients: Y Huang, \\ F Chen; (IV) Collection and assembly of data: Y Huang, F Chen, L Huang; (V) Data analysis and interpretation: G Xu, F Chen; (VI) Manuscript \\ writing: All authors; (VII) Final approval of manuscript: All authors. \\ "These authors contributed equally to this work. \\ Correspondence to: Dr. Congying Chen; Dr Lijuan Yang. Department of Gastroenterology, Shanghai General Hospital, Shanghai Jiao Tong University \\ School of Medicine, 100 Haining Road, Hongkou District, Shanghai 200080, China. Email: cherrychencong@163.com; humourlife001@163.com.
}

\begin{abstract}
Background: The colonoscopy withdrawal time (WT) and adenoma detection rate (ADR) are widely used quality indicators for colonoscopy. However, no study has investigated the appropriate colonoscopy WTs of individual colonic segments that will allow trainees to achieve a higher ADR. Thus, we analyzed for the first time the relationship between colonoscopy WT and the ADR/polyp detection rate (PDR) in the proximal, left-sided and entire colon among trainees.
\end{abstract}

Methods: This retrospective study involved 611 consecutive patients who underwent colonoscopy from March 2018 to March 2019 performed by 6 trainees in the Endoscopy Center of Shanghai General Hospital. The WTs for the individual colonic segments and any significant findings of colonoscopies were retrospectively retrieved from the trainees' records and verified in the endoscopy center database. ADR/PDR was defined as the number of colonoscopies detecting at least 1 polyp/adenoma divided by the total number of colonoscopies. Comparisons of PDR and ADR between the 2 groups were conducted using chi-square test. Multilevel analysis was performed to consider individual differences among the 6 trainees. Multilevel binary logistic regression analysis was performed to analyze the factors that influenced the PDR, ADR and advanced adenoma detection rate (AADR) for the entire colon, and trainee status was included as a random effect.

Results: The mean WTs were $4.20 \pm 1.09,4.27 \pm 1.12$, and $8.48 \pm 1.87$ minutes for the proximal, left-sided, and entire colon, respectively. A longer WT [odds ratio (OR) 1.499, 95\% confidence interval (CI): 1.3811.628, $\mathrm{P}<0.001$; OR 1.409, 95\% CI: $1.265-1.569, \mathrm{P}<0.001$, respectively] was significantly associated with a higher PDR and ADR. The PDR $(\mathrm{P}<0.001)$ and ADR $(\mathrm{P}<0.001)$ were significantly higher when the WT was $>4$ minutes than when the WT was $\leq 4$ minutes in both the proximal and left-sided colon, while the PDR $(\mathrm{P}<0.001)$ and $\mathrm{ADR}(\mathrm{P}<0.001)$ were significantly higher when the $\mathrm{WT}$ was $>8$ minutes in the entire colon.

Conclusions: In order to improve trainee colonoscopy performance, trainees were recommended to have WTs of at least 4 minutes in the proximal colon, 4 minutes in the left-sided colon and 8 minutes in the entire colon during negative screening colonoscopies.

Keywords: Colonoscopy withdrawal time; adenoma detection rate (ADR); trainee; proximal colon; left-sided colon

Submitted Mar 17, 2021. Accepted for publication Jul 07, 2021.

doi: 10.21037/apm-21-622

View this article at: https://dx.doi.org/10.21037/apm-21-622 


\section{Introduction}

Endoscopy training is an important component of postgraduate gastroenterology programs $(1,2)$. In recent years, a 3-year fellowship training program for gastroenterologists has been conducted in China, which includes endoscopy training. With an increasing number of physicians being trained in the practice of gastrointestinal endoscopy in gastroenterology departments in China, previously unnoticed problems have become increasingly obvious. Our foremost consideration is to ensure high-quality colonoscopies performed by trainees to provide optimal treatment for our patients. While multiple studies have investigated the minimal number of colonoscopies a trainee needs to perform before reaching satisfactory proficiency in colonoscopies, few studies have examined how colonoscopies should be performed by trainees during their learning period to both maximize the quality of the procedure for their patients and meet the trainees' educational goals. Studies have shown that colonoscopy quality is closely related to many factors, including patient factors (age, sex, race, underlying disease), cecal intubation, bowel preparation quality, careful examination of mucosal surfaces, colonoscopy withdrawal time (WT), and procedure time (1,3-13). Moreover, studies have shown that the skill of individual endoscopist and the withdrawal technique are also related to colonoscopy quality (13). Regarding trainees, some studies have shown that colonoscopy quality is positively correlated with training time $(14,15)$. However, a study examining the overall consistency of lesion detection by year of training suggested that with adequate attending supervision, even inexperienced trainees can perform highquality colonoscopies (16). Moreover, other studies showed the trainees' WT and cecal intubation time of trainees decreased with the level of training, but the quality of colonoscopy was not significantly different (17). To date, no studies have reported the influence of trainee background, age, gender and personality on colonoscopy quality.

Colorectal adenoma, especially villous adenoma, is an important precancerous disease associated with colorectal cancer (CRC). Studies have shown that male sex, advanced age, smoking, drinking, obesity, lack of exercise and a low-fiber diet are prominent risk factors for colorectal polyps and adenomas $(4,18-20)$. In terms of diagnostics, the American Society of Gastroenterology recommends colonoscopy as the first choice for screening for colorectal tumors. The adenoma detection rate (ADR) is considered an indicator of the quality of colonoscopy procedures (21).
However, the ADR of different adenoma types fluctuates from $20 \%$ to $46.5 \%$, and the ADR of different operators fluctuates from $21 \%$ to $86 \%$ (22). One meta-analysis showed that the adenoma miss rate (AMR) could be as high as $22 \%$ in some studies. Corley et al. (23) showed that for every $1 \%$ increase in the operator's $\mathrm{ADR}$, the risk of interphase CRC was decreased by $3 \%$, and the risk of fatal interphase CRC was decreased by $5 \%$. Therefore, improving the lesion detection rate of operators and reducing false-negative diagnoses are crucially important.

The colonoscopy WT and ADR are widely used quality indicators for colonoscopy performed by trainees $(11,24)$. Multiple studies have shown that a prolonged WT in colonoscopies performed by skilled endoscopists results in a higher $\operatorname{ADR}(25,26)$, and $a \geq 6$-minute average $W T$ in negative screening colonoscopies is recommended by the American Society for Gastrointestinal Endoscopy (27). Barclay et al. (3) observed a dramatic increase in the ADR for endoscopists with a mean $\mathrm{WT}>6$ minutes compared with those with a WT $<6$ minutes $(28 \%$ vs. $12 \%)$; the mean WT was $6.3 \pm 3.9$ minutes. To date, only one study by Gromski et al. (28), has discussed the WT during colonoscopy performed by trainees and recommended an average $W T$ of $\geq 10$ minutes in negative screening colonoscopies for first-year trainees; the mean WT was $10.2 \pm 3.4$ minutes. A recent multicenter prospective observational study by Jung et al. (29) investigated the relationship between the $\mathrm{WT}$ and ADR/polyp detection rate (PDR) in individual colonic segments, and they found that the PDR and ADR appeared to be significantly increased when the WT was $\geq 2$ minutes in the right-sided colon segment, $\geq 4$ minutes in the proximal colon, and $\geq 3$ minutes in the left-sided colon segment compared with when the WT was shorter. Based on these findings and our clinical observations, we hypothesized that for trainee operators, it might be more appropriate to consider specific WTs for individual colonic segments (including the proximal and left-sided colon segments) instead of examining an overall time frame. To the best of our knowledge, the relationship between WTs and the ADR/PDR in individual colonic segments for trainees has not been studied. Thus, the aim of this study was to evaluate the relationship between the colonoscopy WTs and the ADR/PDR in individual colonic segments for trainees to determine the optimal WT for the proximal and left-sided colon segments.

We present the following article in accordance with the STROBE reporting checklist (available at https://dx.doi. org/10.21037/apm-21-622). 


\section{Methods}

\section{Study population and design}

This was a retrospective study involving 611 consecutive patients who underwent screening colonoscopy from March 2018 to March 2019 performed by 6 trainees in the Endoscopy Center of Shanghai General Hospital. The 6 trainees were second-year gastroenterology fellows who had just reached competency in performing independent colonoscopy based on two objective criteria: (I) adjusted completion rate $(>90 \%)$, and (II) cecal intubation time ( $<20$ minutes). The patient exclusion criteria were as follows: (I) emergency colonoscopy; (II) previous history of colonic operations; (III) surveillance of inflammatory bowel disease; (IV) unacceptable bowel preparation (solid); (V) age older than 80 years or younger than age 18 years, and (VI) difficulties identifying the hepatic flexure. This study was reviewed and approved by the Ethical Committee of Shanghai General Hospital affiliated with Shanghai Jiao Tong University School of Medicine (Study number: 2020 ke 042). The study was conducted in accordance with the Declaration of Helsinki (as revised in 2013).

\section{Data collection}

Olympus CF-260 video colonoscopes (Olympus Optical Co., Ltd., Tokyo, Japan) were used for all procedures without a distal attachment cap, and the colonoscopies were performed by using the "single-handed" technique under anesthesiologist-assisted sedation. For quality control and based on the hospital training guideline protocol, each trainee $(n=6)$ was requested to record their colonoscopy performance with a self-assessment form including patient demographics, sedation technique, colonoscopy insertion time, WT from the proximal colon segment, the leftsided colon segment, and entire colons, diagnosis and any significant findings. The colonoscopic WT was recorded with a stopwatch. The amount of time that elapsed during biopsies or polyp removal was measured and subtracted from the WT. The trainees were instructed to perform a WT during negative screening colonoscopies of more than 6 minutes. Data were retrospectively extracted from the trainees' records and verified in the endoscopy center database, which consists of images, with operation times shown on the corner, obtained during the whole colonoscopy procedure. The splenic flexure was defined by the bluish hue from the adjacent spleen, which was observed during colonoscopy withdrawal. In this retrospective study, patient demographics, colonoscopy insertion times, WTs for the proximal colon segment, left-sided colon segment, and entire colon, and polyp histologic type (hyperplastic, adenoma, advanced adenoma, or adenocarcinoma) were included for further analysis.

\section{Definitions of factors}

The following measurements were calculated for each colonic segment and the entire colon: PDR, defined as the number of colonoscopies detecting at least 1 polyp divided by the total number of colonoscopies; ADR, defined as the number of colonoscopies detecting at least 1 adenoma divided by the total number of colonoscopies; and advanced adenoma detection rate (AADR), defined as the number of colonoscopies detecting at least 1 advanced adenoma divided by the total number of colonoscopies. We sought to identify correlations of the WT with the PDR, ADR and AADR in individual colonic segments.

\section{Statistical analysis}

Data are expressed as the means \pm standard deviation or numbers with percentages. Comparisons of PDR, ADR and AADR between the 2 groups were conducted using chisquare test. We used the Pearson correlation coefficient to evaluate the relationship between the WTs and ADRs of the trainees. Multilevel binary logistic regression analysis was performed to analyze the factors that influenced the PDR, $\mathrm{ADR}$ and $\mathrm{AADR}$ in the entire colon, and trainee status was included as a random effect; the WT and insertion time are regarded as dependent variables and age while sex and bowel preparation as independent variables. A probability level of $\mathrm{P}<0.05$ (two-sided) was considered statistically significant. All analyses were performed using SPSS software (version 25.0, IBM, Armonk, NY, USA).

\section{Results}

\section{Baseline characteristics of the patients and colonoscopies}

According to the inclusion and exclusion criteria, a total of 611 patients $(50.4 \%$ men, $49.6 \%$ women) who were successfully examined by the 6 trainees were enrolled (Figure 1). The mean age of the patients was 55.98 \pm 13.49 years (Table 1 ). The mean insertion time into the cecum was $12.44 \pm 3.37$ minutes, and the mean WTs were $4.20 \pm 1.09$ minutes for the proximal colon, 4.27 


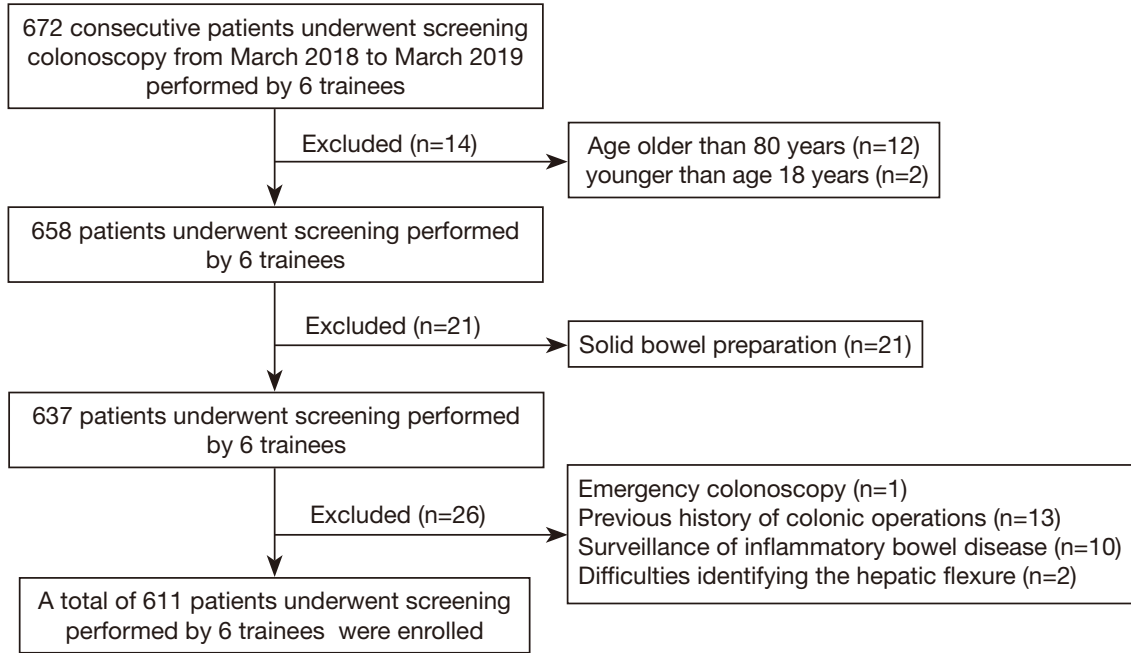

Figure 1 Flow diagram of enrollment for this study.

Table 1 Baseline characteristics of the patients and colonoscopies

\begin{tabular}{|c|c|c|}
\hline Characteristics & $\begin{array}{l}\text { No. of patients } \\
\qquad(\mathrm{N}=611)\end{array}$ & $\begin{array}{c}\text { Percentage of } \\
\text { patients (\%) }\end{array}$ \\
\hline \multicolumn{3}{|c|}{ Age at colonoscopy, years } \\
\hline$<50$ & 166 & 27.2 \\
\hline $50-59$ & 153 & 25.0 \\
\hline $60-69$ & 213 & 34.9 \\
\hline$\geq 70$ & 79 & 12.9 \\
\hline \multicolumn{3}{|l|}{ Sex } \\
\hline Male & 308 & 50.4 \\
\hline Female & 303 & 49.6 \\
\hline \multicolumn{3}{|c|}{ Indication for colonoscopy } \\
\hline Screening & 320 & 52.4 \\
\hline Abdominal pain & 87 & 14.2 \\
\hline $\begin{array}{l}\text { Bowel habit } \\
\text { change }\end{array}$ & 101 & 16.5 \\
\hline Surveillance & 57 & 9.3 \\
\hline Familial history & 8 & 1.3 \\
\hline Others & 38 & 6.2 \\
\hline \multicolumn{3}{|l|}{ Bowel preparation } \\
\hline Excellent or good & 513 & 84.0 \\
\hline Fair & 98 & 16.0 \\
\hline
\end{tabular}

\pm 1.12 minutes for the left-sided colon segment, and $8.48 \pm 1.87$ minutes for the entire colon.

\section{Baseline characteristics of the trainees and colonoscopies performed by trainees}

The 6 trainees ( 4 females and 2 males) were second-year gastroenterology fellows who had just reached competency in performing independent colonoscopy. The mean age of the trainees was $32.17 \pm 1.47$ years (Table 2). Four trainees have $\mathrm{Ph} . \mathrm{D}$. degrees while 2 have master's degrees. When they entered the training, the trainees did not have previous experience in gastrointestinal endoscopy. The insertion time into the cecum and WTs are listed in Table 2.

\section{Factors associated with the PDR, ADR and AADR in the entire colon}

The bowel preparation, size or level differences between colonoscopy operation units, cecal insertion rate, WT and polyp size and shape were the main factors that affect the ADR $(30,31)$. The associations between patientrelated, colonoscopy-related and the detection of polyps, adenomas and advanced adenomas in the entire colon when trainee status was considered as a random effect are summarized in Table 3. Significantly more polyps and adenomas were detected in elderly patients and men. 
Table 2 Baseline characteristics of the trainees and colonoscopies performed by trainees

\begin{tabular}{|c|c|c|c|c|c|c|}
\hline Trainee & \multicolumn{3}{|c|}{ Characteristics } & \multicolumn{3}{|c|}{ Colonoscopies performed by trainees } \\
\hline A & 33 & Female & Ph.D. & 103 & $12.33 \pm 3.16$ & $8.50 \pm 1.86$ \\
\hline B & 32 & Female & Ph.D. & 100 & $12.24 \pm 3.12$ & $8.36 \pm 1.81$ \\
\hline C & 30 & Male & Ph.D. & 99 & $12.34 \pm 3.38$ & $8.58 \pm 1.85$ \\
\hline E & 34 & Female & Ph.D. & 100 & $12.82 \pm 3.71$ & $8.55 \pm 1.87$ \\
\hline $\mathrm{F}$ & 36 & Female & Master's degree & 104 & $12.55 \pm 3.77$ & $8.43 \pm 1.94$ \\
\hline Total & $32.17 \pm 1.47$ & - & - & 611 & $12.44 \pm 3.37$ & $8.48 \pm 1.87$ \\
\hline
\end{tabular}

Table 3 Factors associated with PDR, ADR and AADR in the total colon

\begin{tabular}{|c|c|c|c|c|c|c|c|c|c|}
\hline Factor & \multicolumn{3}{|c|}{ PDR } & \multicolumn{3}{|c|}{ ADR } & \multicolumn{3}{|c|}{ AADR } \\
\hline Age, years & 1.052 & $1.043-1.061$ & $<0.001$ & 1.048 & $1.028-1.069$ & $<0.001$ & 1.049 & $1.003-1.098$ & 0.036 \\
\hline Sex (female) & 2.185 & $1.326-3.603$ & 0.002 & 2.343 & $1.220-4.499$ & 0.020 & 2.287 & $1.748-9.141$ & 0.185 \\
\hline Bowel preparation (fair) & 0.860 & $0.524-1.412$ & 0.551 & 0.939 & $0.428-2.060$ & 0.845 & 0.590 & $0.362-7.950$ & 0.420 \\
\hline Withdrawal time & 1.499 & $1.381-1.628$ & $<0.001$ & 1.409 & $1.265-1.569$ & $<0.001$ & 1.378 & $1.113-1.705$ & 0.003 \\
\hline
\end{tabular}

$\mathrm{P}<0.05$ is two-sided. PDR, polyp detection rate; $\mathrm{ADR}$, adenoma detection rate; $\mathrm{AADR}$, advanced adenoma detection rate; OR, odds ratio; $\mathrm{Cl}$, confidence interval.

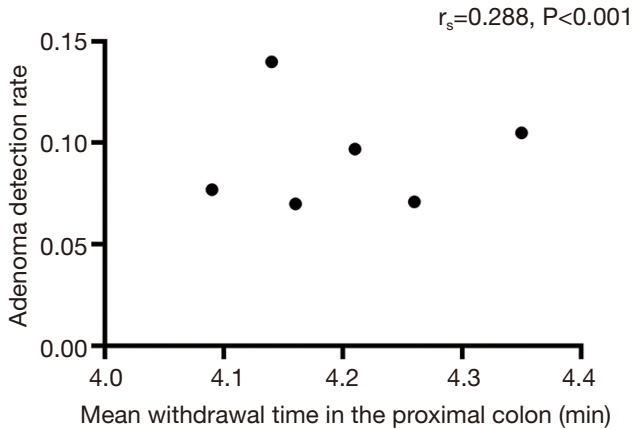

Figure 2 Positive weak correlation between WT and ADR in the proximal colon for 6 trainees, using Spearman rank-correlation analysis. WT, withdrawal time; $\mathrm{ADR}$, adenoma detection rate.

Regarding colonoscopy-related factors, the insertion time had no effect on the PDR, ADR or AADR. A longer WT was significantly associated with a higher PDR, ADR and AADR [odds ratio (OR) 1.499, 95\% confidence interval (CI): 1.381-1.628, $\mathrm{P}<0.001$; OR 1.409, 95\% CI: $1.265-$

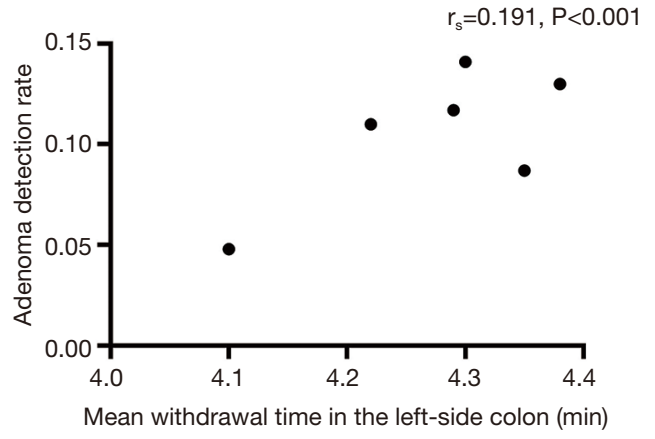

Figure 3 Positive weak correlation between WT and ADR in the left-sided colon for 6 trainees, using Spearman rank-correlation analysis. WT, withdrawal time; ADR, adenoma detection rate.

1.569, $\mathrm{P}<0.001$; OR 1.378, 95\% CI: $1.113-1.705, \mathrm{P}=0.003$, respectively]. A weak positive correlation was observed between the WT and ADR in the proximal, left-sided and entire colon according to the Spearman rank-correlation analysis (Figures 2-4). 


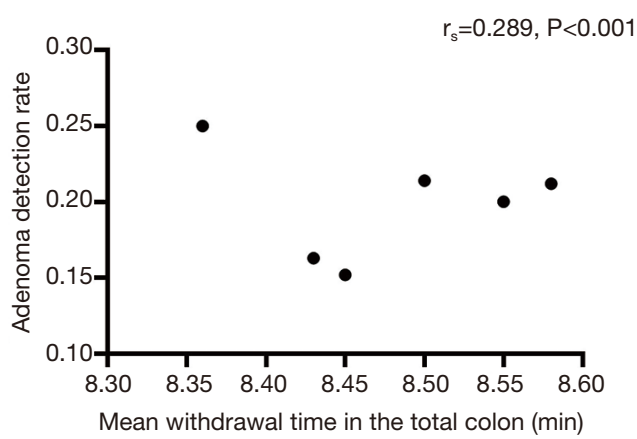

Figure 4 Positive weak correlation between WT and ADR in the total colon for 6 trainees, using Spearman rank-correlation analysis. WT, withdrawal time; ADR, adenoma detection rate.

Table 4 Overall results for each trainee with respect to the entire colon

\begin{tabular}{lccc}
\hline Trainee & PDR $(\%)$ & ADR $(\%)$ & AADR $(\%)$ \\
\hline A & 30.1 & 21.4 & 2.9 \\
B & 31.0 & 25.0 & 7.0 \\
C & 32.3 & 21.2 & 1.0 \\
D & 28.6 & 15.2 & 3.8 \\
E & 32.0 & 20.0 & 3.0 \\
F & 22.1 & 16.3 & 1.9 \\
Total & 29.3 & 19.8 & 3.3 \\
\hline
\end{tabular}

PDR, polyp detection rate; ADR, adenoma detection rate; AADR, advanced adenoma detection rate.

\section{Lesion detection rates}

The respective PDR, ADR, and AADR were 12.3\%, 9.3\%, and $1.3 \%$ for the proximal colon segment, $17.0 \%, 10.5 \%$, and $2.0 \%$ for the left-sided colon segment, and $29.3 \%$, $19.8 \%$, and $3.3 \%$ for the entire colon. The PDR, ADR and AADR of each trainee are listed in Table 4; the PDR, ADR and AADR of each trainee for individual colonic segments are given in Table 5 .

\section{Lesion detection rates according to the mean WT}

According to the studies reviewed above $(3,28)$, the rounded value of the mean time of WT was typically used as the cutoff value for the WT. The mean WTs were $4.20 \pm 1.09$ minutes for the proximal colon, $4.27 \pm 1.12$ minutes for the leftsided colon segment, and $8.48 \pm 1.87$ minutes for the entire colon; therefore, we used 4 minutes as the cutoff time for the proximal colon and left-sided colon and 8 minutes for the entire colon. In the proximal colon segment, the PDR (26.8\% vs. $5.7 \%, \mathrm{P}<0.001)$, ADR $(20.5 \%$ vs. $4.3 \%, \mathrm{P}<0.001)$, and AADR ( $3.2 \%$ vs. $0.5 \%, \mathrm{P}=0.007)$ were significantly higher when the WT was $>4$ minutes than when the WT was $\leq 4$ minutes. In the left-sided colon, the PDR $(28.0 \% v s$. $11.4 \%, \mathrm{P}<0.001)$ and $\mathrm{ADR}(17.4 \%$ vs. $6.9 \%, \mathrm{P}<0.001)$ were significantly higher when the WT was $>4$ minutes than when the $W T$ was $\leq 4$ minutes, while the AADR $(2.9 \%$ vs. $1.5 \%, \mathrm{P}=0.233)$ showed no significant differences among different WTs. Finally, in the entire colon, the PDR (53.6\% vs. $16.8 \%, \mathrm{P}<0.001), \operatorname{ADR}(36.2 \%$ vs. $11.4 \%, \mathrm{P}<0.001)$, and $\operatorname{AADR}(6.3 \%$ vs. $1.7 \%, \mathrm{P}=0.03)$ were significantly higher when the WT was $>8$ minutes than when the WT was $\leq 8$ minutes (Table 6).

\section{Discussion}

The ADRs of 6 trainees enrolled in the fellowship training program of our hospital were analyzed retrospectively. The mean ADR among the trainees was $19.8 \%$, which was much lower than that of experienced operators (32). In accordance with literature reports, we suggest that this finding is related to the proficiency and theoretical knowledge of the novice operators $(17,28,33)$. As many of the factors that influence the ADR and PDR are inherent to patients undergoing colonoscopy, colonoscopy WT is considered a highly important parameter, as it is an amendable factor related to the ADR (34). At present, it is generally accepted that a WT of at least 6 to 7 minutes is necessary to reliably achieve an ADR of $25 \%$ or higher $(35,36)$. While a prolonged WT has a positive effect on the ADR, the effect continuously decreases and eventually disappears. Moreover, the number of polyps detected did not improve as the $\mathrm{WT}$ was lengthened. Simmons et al. (37) analyzed the relationship between the colonoscopy WTs of experienced operators and the PDR in 10,955 patients and showed that the PDR of polyps with different diameters was greater than $50 \%$ and that the PDR of polyps with diameters less than $20 \mathrm{~mm}$ increased to $65 \%$ when the WT was 7 minutes. However, the PDR of polyps measuring larger than $20 \mathrm{~mm}$ did not increase as the WT changed.

Furthermore, in a study by Barclay et al. (38), a higher $\mathrm{ADR}$ was observed when the WT was at least 8 minutes (34.7\% vs. $23.5 \%, \mathrm{P}<0.01)$. Notably, regarding trainee operators, prolonging the WT to $>10$ minutes led to a significantly higher ADR of $32.3 \%$ (vs. $9.5 \%$ for WTs $\leq 10$ minutes) (28). Similarly, in our study, we found a 
Table 5 Results for each trainee with respect to individual colonic segments

\begin{tabular}{|c|c|c|c|c|c|c|c|c|}
\hline Trainee & \multicolumn{4}{|c|}{ Proximal colon } & \multicolumn{4}{|c|}{ Left side of the colon } \\
\hline A & $4.21 \pm 1.09$ & 12.6 & 9.7 & 1.9 & $4.29 \pm 1.08$ & 17.5 & 11.7 & 1.0 \\
\hline$B$ & $4.14 \pm 1.11$ & 16.0 & 14.0 & 3.0 & $4.22 \pm 1.07$ & 15.0 & 11.0 & 4.0 \\
\hline C & $4.26 \pm 1.04$ & 8.1 & 7.1 & 0 & $4.30 \pm 1.15$ & 24.2 & 14.1 & 1.0 \\
\hline$E$ & $4.16 \pm 1.11$ & 10.0 & 7.0 & 1.0 & $4.38 \pm 1.11$ & 22.0 & 13.0 & 2.0 \\
\hline $\mathrm{F}$ & $4.09 \pm 1.12$ & 10.6 & 7.7 & 0 & $4.35 \pm 1.17$ & 11.5 & 8.7 & 1.9 \\
\hline Total & $4.20 \pm 1.09$ & 12.3 & 9.3 & 1.3 & $4.27 \pm 1.12$ & 17.0 & 10.5 & 2.0 \\
\hline
\end{tabular}

WT, withdrawal time; PDR, polyp detection rate; ADR, adenoma detection rate; AADR, advanced adenoma detection rate.

Table 6 Detection rate of lesions according to the mean WT by using chi-square test

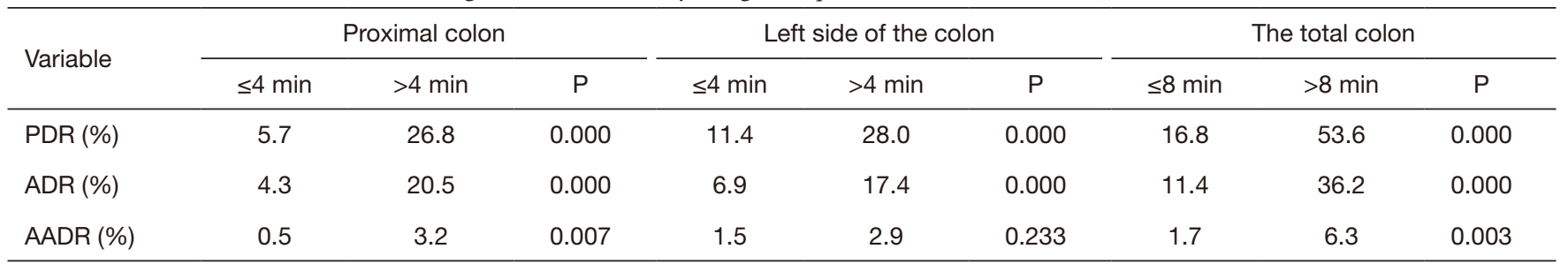

WT, withdrawal time; PDR, polyp detection rate; $A D R$, adenoma detection rate; AADR, advanced adenoma detection rate.

statistically significant difference in the ADR between WTs $>8$ and $\leq 8$ minutes $(36.2 \%$ and $11.4 \%$, respectively) among the second-year trainee endoscopists. We therefore recommend a $\mathrm{WT}$ of at least 8 minutes for trainees during negative screening colonoscopies.

Current studies of the optimal WT mostly focus on the withdrawal process as a whole $(1,3,39)$; however, as the leftsided and right-sided colon have anatomic features that create distinct challenges for meticulous inspection, the ideal time distribution for individual colon segments should be carefully analyzed. The left-sided colon is anatomically more curved, making slips of the endoscope more likely and increasing the difficulty of controlling scope withdrawal. In contrast, the colon pocket of the right-sided colon is deep and can hide adenomas and polyps, making false-negative results likely. It is possible that an operator could spend most of the WT observing the rectum and sigmoid colon to maintain a WT of 6 minutes while reducing the time spent in the proximal colon. Yun et al. (40) first reported the correlation between the WT in the right-sided colon segment and the ADR; thus, we suggest that it would be beneficial to not excessively focus on the overall WT but to consider the optimal WT for each colonic segment.

In our study, for the proximal colon segment, a WT $>4$ minutes led to significant improvements (vs. times $\leq 4$ minutes) in the PDR (26.8\% vs. $5.7 \%, \mathrm{P}<0.001)$, ADR (20.5\% vs. $4.3 \%, \mathrm{P}<0.001)$, and $\mathrm{AADR}(3.2 \%$ vs. $0.5 \%$, $\mathrm{P}<0.01)$. In the left-sided colon, a similar trend could be observed; the PDR $(28.0 \%$ vs. $11.4 \%, \mathrm{P}<0.001)$ and ADR $(17.4 \%$ vs. $6.9 \%, \mathrm{P}<0.001)$ were significantly higher when the WT was $>4$ minutes than when the WT was $\leq 4$ minutes.

There are several limitations of this study. First, this is a single-center retrospective study that only focuses on the effect of the WT on the PDR/ADR, which might cause bias. Among the factors that are difficult to control are changes in the patient's position and the use of different endoscopic techniques, such as folds visualizing techniques. Second, the mean WTs in the proximal colon and the whole colon were similar among trainees due to limitations of the retrospective methodology. Additionally, the analysis was not adjusted for patient factors, such as age, sex, family history of CRC, smoking, drinking, obesity, lack of exercise, and low-fiber diet. In addition, we did not perform image- 
guided colonoscopy to accurately distinguish the colon segments. However, the amount of time taken for biopsies or polyp removal was measured and subtracted from the WT. Furthermore, based on this study, we are performing further prospective studies to investigate the WTs from individual colonic segments for trainees, which may provide more appropriate recommendations for trainees in the future.

\section{Conclusions}

Considerable variation among endoscopists has been reported in the literature. To diminish this disparity, choosing reasonable WTs is essential to systemically control and improve the quality of colonoscopies performed by trainee endoscopists. To date, we are not aware of any studies suggesting colonoscopy WTs according to individual colonic segments for trainee endoscopists. In our study, during negative screening colonoscopies, the PDR and ADR significantly increased when the WTs were $>4$ minutes in the proximal colon and $>4$ minutes in the left-sided colon segment compared to when the WTs were shorter. Based on our results, we recommend a WT of at least 4 minutes in the proximal colon and 4 minutes in the left side colon for trainees during negative screening colonoscopy.

\section{Acknowledgments}

We would like to thank the American Journal Experts for language editing.

Funding: None.

\section{Footnote}

Reporting Checklist: The authors have completed the STROBE reporting checklist. Available at https://dx.doi. org/10.21037/apm-21-622

Data Sharing Statement: Available at https://dx.doi. org/10.21037/apm-21-622

Conflicts of Interest: All authors have completed the ICMJE uniform disclosure form (available at https://dx.doi. org/10.21037/apm-21-622). The authors have no conflicts of interest to declare.

Ethical Statement: The authors are accountable for all aspects of the work in ensuring that questions related to the accuracy or integrity of any part of the work are appropriately investigated and resolved. The study was conducted in accordance with the Declaration of Helsinki (as revised in 2013). This study was reviewed and approved by the Ethical Committee of Shanghai General Hospital affiliated with Shanghai Jiao Tong University School of Medicine (study number 2020 ke 042). Individual consent for this retrospective analysis was waived.

Open Access Statement: This is an Open Access article distributed in accordance with the Creative Commons Attribution-NonCommercial-NoDerivs 4.0 International License (CC BY-NC-ND 4.0), which permits the noncommercial replication and distribution of the article with the strict proviso that no changes or edits are made and the original work is properly cited (including links to both the formal publication through the relevant DOI and the license). See: https://creativecommons.org/licenses/by-nc-nd/4.0/.

\section{References}

1. Evans B, Pace D, Borgaonkar M, et al. Effect of an educational intervention on colonoscopy quality outcomes. Surg Endosc 2020;34:5142-7.

2. Hope WW, Hooks WB 3rd, Kilbourne SN, et al. Assessing resident performance and training of colonoscopy in a general surgery training program. Surg Endosc 2013;27:1706-10.

3. Barclay RL, Vicari JJ, Doughty AS, et al. Colonoscopic withdrawal times and adenoma detection during screening colonoscopy. N Engl J Med 2006;355:2533-41.

4. Kaminski MF, Regula J, Kraszewska E, et al. Quality indicators for colonoscopy and the risk of interval cancer. N Engl J Med 2010;362:1795-803.

5. Corley DA, Jensen CD, Marks AR, et al. Variation of adenoma prevalence by age, sex, race, and colon location in a large population: implications for screening and quality programs. Clin Gastroenterol Hepatol 2013;11:172-80.

6. Jrebi NY, Hefty M, Jalouta T, et al. High-definition colonoscopy increases adenoma detection rate. Surg Endosc 2017;31:78-84.

7. Jung DH, Lee JI, Huh CW, et al. Withdrawal time of 8 minutes is associated with higher adenoma detection rates in surveillance colonoscopy after surgery for colorectal cancer. Surg Endosc 2021;35:2354-61.

8. Kravochuck S, Gao R, Church J. Differences in colonoscopy technique impact quality. Surg Endosc 2014;28:1588-93. 
9. Li P, Ma B, Gong S, et al. Effect of dynamic position changes during colonoscope withdrawal: a metaanalysis of randomized controlled trials. Surg Endosc 2021;35:1171-81.

10. Teng TY, Khor SN, Kailasam M, et al. Morning colonoscopies are associated with improved adenoma detection rates. Surg Endosc 2016;30:1796-803.

11. Ende AR, De Groen P, Balmadrid BL, et al. Objective Differences in Colonoscopy Technique Between Trainee and Expert Endoscopists Using the Colonoscopy Force Monitor. Dig Dis Sci 2018;63:46-52.

12. Akanbi O, Adejumo AC. Early Endoscopy Is Associated with Better Clinical Outcomes in Patients Hospitalized with Ischemic Bowel Disease. Dig Dis Sci 2019;64:2467-77.

13. Jawitz NG, Gellad ZF, Lin L, et al. Patient, Physician, and Procedure Characteristics Are Independently Predictive of Polyp Detection Rates in Clinical Practice. Dig Dis Sci 2021;66:2570-7.

14. Gianotti RJ, Oza SS, Tapper EB, et al. A Longitudinal Study of Adenoma Detection Rate in Gastroenterology Fellowship Training. Dig Dis Sci 2016;61:2831-7.

15. Rex DK. Colonoscopic withdrawal technique is associated with adenoma miss rates. Gastrointest Endosc 2000;51:33-6.

16. Chen SC, Rex DK. Endoscopist can be more powerful than age and male gender in predicting adenoma detection at colonoscopy. Am J Gastroenterol 2007;102:856-61.

17. Singh S. Colonoscopy withdrawal time and adenoma detection rates for trainees. Surg Endosc 2013;27:2243-4.

18. Ben Q, An W, Jiang Y, et al. Body mass index increases risk for colorectal adenomas based on meta-analysis. Gastroenterology 2012;142:762-72.

19. Hermann S, Rohrmann S, Linseisen J. Lifestyle factors, obesity and the risk of colorectal adenomas in EPICHeidelberg. Cancer Causes Control 2009;20:1397-408.

20. Ng S, Sreenivasan AK, Pecoriello J, et al. Polyp Detection Rate Correlates Strongly with Adenoma Detection Rate in Trainee Endoscopists. Dig Dis Sci 2020;65:2229-33.

21. American Gastroenterology Association. AGA institute guidelines for colonoscopy surveillance after cancer resection: clinical decision tool. Gastroenterology 2014;146:1413-4.

22. van Rijn JC, Reitsma JB, Stoker J, et al. Polyp miss rate determined by tandem colonoscopy: a systematic review. Am J Gastroenterol 2006;101:343-50.

23. Corley DA, Jensen CD, Marks AR, et al. Adenoma detection rate and risk of colorectal cancer and death. $\mathrm{N}$ Engl J Med 2014;370:1298-306.
24. Rex DK, Bond JH, Winawer S, et al. Quality in the technical performance of colonoscopy and the continuous quality improvement process for colonoscopy: recommendations of the U.S. Multi-Society Task Force on Colorectal Cancer. Am J Gastroenterol 2002;97:1296-308.

25. Kumar S, Thosani N, Ladabaum U, et al. Adenoma miss rates associated with a 3 -minute versus 6 -minute colonoscopy withdrawal time: a prospective, randomized trial. Gastrointest Endosc 2017;85:1273-80.

26. Wong WJ, Arafat Y, Wang S, et al. Colonoscopy withdrawal time and polyp/adenoma detection rate: a single-site retrospective study in regional Queensland. ANZ J Surg 2020;90:314-6.

27. Rex DK, Schoenfeld PS, Cohen J, et al. Quality indicators for colonoscopy. Gastrointest Endosc 2015;81:31-53.

28. Gromski MA, Miller CA, Lee SH, et al. Trainees' adenoma detection rate is higher if $\geq 10$ minutes is spent on withdrawal during colonoscopy. Surg Endosc 2012;26:1337-42.

29. Jung Y, Joo YE, Kim HG, et al. Relationship between the endoscopic withdrawal time and adenoma/polyp detection rate in individual colonic segments: a KASID multicenter study. Gastrointest Endosc 2019;89:523-30.

30. Ben-Horin S, Bar-Meir S, Avidan B. The impact of colon cleanliness assessment on endoscopists' recommendations for follow-up colonoscopy. Am J Gastroenterol 2007;102:2680-5

31. Wolin KY, Yan Y, Colditz GA. Physical activity and risk of colon adenoma: a meta-analysis. Br J Cancer 2011;104:882-5.

32. le Clercq CM, Mooi RJ, Winkens B, et al. Temporal trends and variability of colonoscopy performance in a gastroenterology practice. Endoscopy 2016;48:248-55.

33. Gromski MA, Lee SH. In response to: Singh S, "Colonoscopy withdrawal time and adenoma detection rates for trainees". Surg Endosc 2013;27:2245-6.

34. Jover R, Zapater P, Polanía E, et al. Modifiable endoscopic factors that influence the adenoma detection rate in colorectal cancer screening colonoscopies. Gastrointest Endosc 2013;77:381-389.e1.

35. Butterly L, Robinson CM, Anderson JC, et al. Serrated and adenomatous polyp detection increases with longer withdrawal time: results from the New Hampshire Colonoscopy Registry. Am J Gastroenterol 2014;109:417-26.

36. Sanaka MR, Parsi MA, Burke CA, et al. Adenoma detection at colonoscopy by polypectomy in withdrawal only versus both insertion and withdrawal: a randomized 
controlled trial. Surg Endosc 2015;29:692-9.

37. Simmons DT, Harewood GC, Baron TH, et al. Impact of endoscopist withdrawal speed on polyp yield: implications for optimal colonoscopy withdrawal time. Aliment Pharmacol Ther 2006;24:965-71.

38. Barclay RL, Vicari JJ, Greenlaw RL. Effect of a timedependent colonoscopic withdrawal protocol on adenoma detection during screening colonoscopy. Clin

Cite this article as: Huang Y, Chen F, Xu G, Huang L, Wan R, Yang L, Chen C. Improving trainee colonoscopy performance by investigating the withdrawal time from individual colonic segments: a single-center observational study. Ann Palliat Med 2021;10(8):8607-8616. doi: 10.21037/apm-21-622
Gastroenterol Hepatol 2008;6:1091-8.

39. Hewett DG, Rex DK. Inspection on instrument insertion during colonoscopy: a randomized controlled trial. Gastrointest Endosc 2012;76:381-7.

40. Yun GY, Eun HS, Kim JS, et al. Colonoscopic withdrawal time and adenoma detection in the right colon. Medicine (Baltimore) 2018;97:e12113. 